\title{
Linking the Ancient Greek WordNet to the Homeric Dependency Lexicon
}

\author{
Chiara Zanchi \\ University of Pavia \\ Corso Strada Nuova 65 \\ I-27100 Pavia PV, Italy \\ chiara.zanchio1@unipv.it
}

\author{
Silvia Luraghi \\ University of Pavia \\ Corso Strada Nuova 65 \\ I-27100 Pavia PV, Italy \\ silvia.luraghi@unipv.it
}

\author{
Erica Biagetti \\ University of Pavia / Bergamo \\ Corso Strada Nuova 65 \\ I-27100 Pavia PV, Italy \\ erica.biagetti01@universitadipavia.it
}

\begin{abstract}
The Ancient Greek WordNet is a new resource that is being developed at the Universities of Pavia and Exeter, based on the Princeton WordNet. The Princeton WordNet provides sentence frames for verb senses, but this type of information is lacking in most WordNets of other languages. In fact, exporting sentence frames from English to other languages is not a trivial task, as sentence frames depend on the syntax of individual languages. In addition, the information provided by the Princeton WordNet is not corpus-based but relies on native speakers' knowledge. This type of information is not available for dead languages, which are by definition corpus languages. In this paper, we show how sentence frames can be extracted from morpho-syntactically parsed corpora by linking an existing dependency lexicon of Homeric verbs (HoDeL) to verbs in the Ancient Greek WordNet. Given its features, HoDeL allows automatically extracting all subcategorization frames available for each verb along with information concerning their frequency as well as semantic information regarding the possible arguments occurring in specific frames. In the paper, we show our method to automatically link the two resources and compare some of the resulting sentence frames with the English sentence frames in the Princeton WordNet.
\end{abstract}

Keywords: WordNet; valency lexica; Ancient Greek; HoDeL; sentence frames

DOI: $10.28995 / 2075-7182-2021-20-729-737$

\section{Извлечение информации для древнегреческого WordNet из Словаря синтаксических зависимостей гомеровского греческого}

\author{
Кьяра Дзанки \\ Университет Павии \\ Corso Strada Nuova 65 \\ I-27100 Pavia PV, Italy \\ silvia.luraghidunipv.it
}

\author{
Сильвия Лураги \\ Университет Павии \\ Corso Strada Nuova 65 \\ I-27100 Pavia PV, Italy \\ chiara.zanchi01@unipv.it
}

\author{
Эрика Бияджетти \\ Университет Павии / Бергамо \\ Corso Strada Nuova 65 \\ I-27100 Pavia PV, Italy \\ erica.biagetti01@universitadipavia.it
}




\section{Introduction}

WordNets (henceforth WNs) are lexical databases in which meaning is stored in a relational way [4]. They comprise nodes for lemmas to which meanings are associated in the form of synsets i.e. sets of cognitive synonyms accompanied by brief definitions. Lemmas are linked to each other by lexical relations, whereas semantic relations interlink synsets, resulting in a network of meaningfully related words and concepts.

In this paper we show how syntactic information can be extracted from a corpus-based dependency lexicon and automatically linked to a WN. Our pilot study ${ }^{1}$ links the Ancient Greek WordNet (AGWN) to the Homeric Dependency Lexicon (HoDeL). In Sec. 2 we illustrate the properties of the AGWN. Sec. 3 contains a brief description of HoDeL and shows how we linked the data. Sec. 4 reviews how syntactic information is provided in some other WNs. In Sec. 5 we survey the sentence frames for two Ancient Greek (AG) verbs. In Sec. 6 we discuss our findings.

\section{The family of WordNets for Ancient Indo-European languages}

The AGWN belongs to a family of WNs for ancient Indo-European (IE) languages, an ongoing project jointly developed at University of Pavia, University of Exeter, and the Center for Hellenic Studies at Harvard University [1]. Besides AG, it currently comprises WNs for Sanskrit and Latin.

The architecture of our WNs aims to facilitate their integration with other resources for ancient languages, adopting a standardized set of lemma-based URIs to guarantee identification (e.g. in the case of ambiguous word forms) and allow easily tying together information from disparate databases (Sec. 2).

The Sanskrit, AG and Latin WNs were designed to be interoperable with each other and to enable the cross-linguistic comparison of linguistic structures. To enhance compatibility, we maximize usage of the synsets deriving from the Princeton English WordNet [4], and adopt a principled view of polysemy, which entails assuming that all literal and non-literal senses of a lemma can be organized in a structured semantic network. Literal senses are detected based on their early attestation, concreteness, and predominance in the network [7], while non-literal senses are divided into metaphorical and metonymical ones. E.g. synsets associated to the AG verb pléo 'sail' are classified as follows:

(1) Literal senses 'sail', 'float'

a. v\#01260993 | travel by boat

b. v\#01299504 | float on the surface of water

(2) Metonymic sense 'depart'

$\mathrm{v} \# 01262245$ | move away from a place into another direction

(3) Metaphoric sense 'behave in a certain way'

$\mathrm{v} \# 00007023$ | behave in a certain manner

For each synset, we provide information on period(s), literary genre(s), author(s), and work(s) in which they are attested. Thus, the senses in (1)a-c feature the metadata in Tab. 1.

\footnotetext{
${ }^{1}$ The Ancient Greek WordNet does not include information about sentence frames, and in this paper we show our first attempts at linking the WordNet semantic information with syntactic information provided by HoDeL starting with two verbs. These verbs do not exhaust the amount of lemmas already annotated in the Ancient Greek WordNet.
} 


\begin{tabular}{|l|l|l|l|}
\hline Sense & Period & Genre & Loci \\
\hline$(1) \mathrm{a}$ & Archaic $\left(8^{\text {th }}-6^{\text {th }}\right.$ BCE $)$ & poetry & Il.3.444, \\
& & epic & Pi.P.4.69 \\
& & $\begin{array}{l}\text { historiography } \\
\text { X.Cyr.6.16 }\end{array}$ & $\begin{array}{l}\text { X.Ag.691 } \\
\end{array}$ \\
& & $\ldots$ & \\
\hline$(2)$ & Archaic $\left(8^{\text {th }}-6^{\text {th }}\right.$ BCE $)$ & epic & Od.12.5 \\
\hline$(3)$ & Classical $\left(5^{\text {th }}\right.$ c.-323 BCE) & theater & S.Ant.190 \\
& & philosophy & D.19.250 \\
& & oratory & Pl.Lg.813d \\
\hline
\end{tabular}

Table 1: Diachronic and stylistic metadata associated with the senses of pléo in (1)-(3)

Diachronic and stylistic metadata are meant to enable studies on semantic change over time and across literary genres and authors.

To allow comparison between the languages of our WNs, we added language-specific features. At the lexical level, we provide each lemma with morphological information, as summarized in Tab. 2.

\begin{tabular}{|l|l|l|}
\hline Field & Subfield & Value \\
\hline Etymology & & PIE. *pleu- 'float' \\
\hline Lemma & & pléō \\
\hline POS & & Verb \\
\hline Morpho & & v1spia--1e \\
\hline Uri & & $\pi 07077$ \\
\hline \multirow{3}{*}{ Morphology } & Principal Parts & $\begin{array}{l}\text { pleúsomai épleusa pépleuka } \\
\text { epléusthēn pleusthésomai pèpleusmai }\end{array}$ \\
\cline { 2 - 3 } & Prosody & pléo \\
\hline \multirow{2}{*}{ Form Tokens } & Form & v1sfia--1e \\
\cline { 2 - 3 } & Token & plesoümai (FUT.IND.1SG) \\
\cline { 2 - 3 } & Alternative & V (late form of pleúsomai) \\
\hline
\end{tabular}

Table 2: Lemma annotation for pléo

We employ an extended set of lexical relations comprising derivation, lexical antonymy with privative $a-$, parasynthesis, composition, inclusion in multi-word expressions, lexicalized participles, exemplified in Tab. 3.

\begin{tabular}{|l|l|l|}
\hline Relation & Label and Example & Inverse \\
\hline Derivation & makró-tēs 'length' IS DERIVED FROM makrós 'long' & IS RELATED TO \\
\hline Antonymy & anomia 'lawlessness' IS PRIVATIVE OF nomia 'lawfulness' & HAS PRIVATIVE \\
\hline Parasynthesis & $\begin{array}{l}\text { ánoos 'without understanding' IS PARASYNTHETIC OF nóos } \\
\text { 'mind' }\end{array}$ & $\begin{array}{l}\text { HAS } \\
\text { PARASYNTHETON }\end{array}$ \\
\hline Composition & $\begin{array}{l}\text { makropoiéó 'enlarge' IS COMPOSED OF makrós 'big'; } \\
\text { makropoiéó 'enlarge' IS COMPOSED OF poiéō 'make' }\end{array}$ & COMPOSES \\
\hline Inclusion & $\begin{array}{l}\text { thalássia érga 'navigation' INCLUDES thalássios 'related to the } \\
\text { sea'; thalássia érga 'navigation' INCLUDES érgon 'work' }\end{array}$ & IS INCLUDED IN \\
\hline Participle & eikốs 'seeming like' IS PARTICIPLE OF éoika 'to be like' & HAS PARTICIPLE \\
\hline
\end{tabular}

Table 3: Family-specific Lexical Relations

\section{Enriching the Ancient Greek WordNet with sentence frames: a pilot study}

As a further step, we aim to integrate sentence frames in the metadata associated to each verbal entry of the AGWN. To do so, we propose a semi-automatic two-step workflow and present a pilot study of Homeric verbs. Ultimately, we aim to enhance the AGWN with sentence frames extracted from the whole Ancient Greek and Latin Dependency Treebank (AGLDT; https://github.com/PerseusDL/treebank_data). Working with the Homeric verbal lexicon has a number of advantages: (i) it allows 
exploiting the user-friendly HoDeL (https:/hodel.unipv.it/hodel-res) to support the annotators' work; (ii) focusing on a limited data-set allows evaluating the efficiency of the automatic step of our workflow.

HoDeL is a corpus-based lexicon of Homeric verbs induced from the Homeric poems treebanked at the AGLDT 2.0. As documented in [8] and [9], HoDeL was obtained with a series of SQL queries extracting from the analytical/syntactic layer of AGLDT 2.0 all finite and nonfinite verbal forms along with some of their child nodes (the ratio of data extraction, its expected and actual output are documented in [8] and [9]). Extracted data was stored in a backend relational database, which lies behind HoDeL online query interface.

HoDeL features most relevant for the purposes of the present paper are the following:

- it allows obtaining corpus-based data concerning sentence frames (in the form of syntactic subtrees), their frequency, and instantiations;

- it gives information about the syntactic (e.g. case marking) and semantic features (e.g. animacy) of verbal dependents;

- it provides aligned translation of Homeric passages.

Thus, HoDeL can be used by annotators with limited expertise on treebanks, .xml, SQL and PML-tree queries. Moreover, it eases the annotators' task to manually pair sentence frames with WN synsets, as it gives translations.

The first step to link HoDeL with the AGWN consisted in automatically mapping the Homeric verbs in HoDeL with the corresponding verbal entries in AGWN. We extracted, for each word in HoDeL backend database, the features 'lemma' and 'postag', and selected only words for which the first value of the postag is ' $\mathrm{v}$ ' i.e. verbs. This extraction yielded 2,482 results. Then, we extracted verbal lemmas from the .csv files of AGWN in the relative Github repository (https://github.com/greekwordnet), selecting the value ' $\mathrm{v}$ ' in the pos fields. This extraction yielded 28,405 results, which represent all verbal lexicon of AG. Finally, we automatically compared the outputs of the two extractions, summarized in Tab. 4:

\begin{tabular}{|l|l|}
\hline $\begin{array}{l}\text { Type of correspondence } \\
\text { (HoDeL-to-Ancient Greek WordNet) }\end{array}$ & Frequency \\
\hline one-to-one & $2,256(90.94 \%)$ \\
\hline one-to-many (two) & $41(1,65 \%)$ \\
\hline one-to-zero & $185(7.41 \%)$ \\
\hline TOTAL & $2,482(100 \%)$ \\
\hline
\end{tabular}

Table 4: Results of the comparison of HoDeL and AGWN verbal lexicon

This pairing attempt is satisfactory, given that more than $90 \%$ of the Homeric verbs found a unique correspondent in the WN: in the vast majority of cases we were able to univocally associate URIs of the AGWN verbs to HoDeL verbs.

Cases of one-to-many correspondences are due to (i) homophonous verbs, represented by ambiguous characters strings, which need to be manually disambiguated: e.g. the string " $\delta \varepsilon \dot{\omega} \omega$ " (BetaCode: de/w) represents verbs assigned URIs " $\delta 01019$ " and " $\delta 01020$ ", corresponding to the meanings 'tie' and "lack'; (ii) verbs contained twice in the AGWN lexicon due to importation errors from the electronic version of the reference dictionary of AGWN, the Liddell-Scott-Jones: e.g. " $\tau \rho \varepsilon ́ \varphi \omega$ " being assigned the URIs $\tau 02408$ and $\tau 02407$ (this error is no longer in AGWN, and thus this study also offered the chance to improve the quality of AGWN base data).

One-to-zero correspondences are due to manyfold factors, which can be clustered as follows:

- different lemmatizations (due to voice (a), dialectal variants (b), pos assignments to defective participles used as nouns or adjectives (c));

- different notations, due to diacritics: hiatus (d), subscript iota (e);

- errors in AGWN: missing verbs (f) and/or incorrect pos assignment (g). 


\begin{tabular}{|c|c|c|}
\hline Mismatch type & HoDeL & AGWN \\
\hline (a) different voice & $\mu \varepsilon \tau \alpha \tau \rho \varepsilon ́ \pi 0 \mu \alpha \mathrm{l}$ & 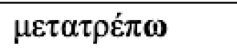 \\
\hline (b) variants & $\delta 1 \alpha \pi \varepsilon ́ \tau \alpha \mu \alpha \imath$ & $\delta 1 \alpha \pi \varepsilon ́ \tau 0 \mu \alpha \imath$ \\
\hline (c) participles & $\theta v \mu \eta \gamma \varepsilon \rho \varepsilon ́ \omega \vee(\mathrm{v})$ & $\theta v \mu \eta \gamma \varepsilon \rho \varepsilon ́ \omega v(\mathrm{n})$ \\
\hline (d) hiatus & 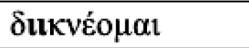 & 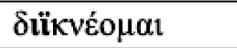 \\
\hline (e) subscript iota & $\theta v \dot{\eta} \sigma \kappa \omega$ & $\theta v \underline{\mid} \sigma \kappa \omega$ \\
\hline (f) missing verbs & $\kappa \alpha \tau \alpha \beta \rho o ́ \chi \omega$ & 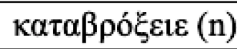 \\
\hline (g) incorrect pos & $\mu \varepsilon ́ \mu o v \alpha$ & 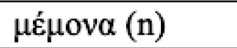 \\
\hline
\end{tabular}

Table 5: Summary of mismatch types

As the number of non-one-to-one correspondences is manually manageable, such mismatches can be fixed. Crucially, this pilot study also helped us identify notations and lemmatizations that require standardization before mapping the entire AG verbal lexicon from AGLDT 2.0 to AGWN.

Once AGWN URIs are assigned to all HoDeL verbs, sentence frames can be imported from the HoDeL backend database into AGWN metadata. Next, we will ask annotators to assign the extracted sentence frames to the correct synsets. Thus, sense disambiguation will be done manually. This task would be much more time-consuming and effortful for the annotators, had HoDeL not provided aligned English translations of the AG passages. Given that sentence frames need to be manually sorted to the correct synsets, it is more convenient to assign them to each lexicon entry while AGWN is still under construction. When the pairing of sentence frames and synsets will be complete, one will be able to determine the frequency distribution of sentence frames, the most frequent filling words for each frame-slot, and their associative connections with synsets, as these data can easily be extracted from HoDeL (synsets make it possible to generalize these associative connections across verbal lexemes).

\section{Syntactic information about verbs' construction in WordNet}

The Princeton WN provides limited information concerning the types of construction in which verbs can occur. It provides 35 sentence frames, which indicate "the number of noun arguments that the verb subcategorizes for" [4]. Verb entries in WN typically contain example sentences for each synset, and may also contain the relevant sentence frames.

E.g. the verb announce has four synsets. The first sense is 'denote' and has four sentence frames, see Fig. 1.

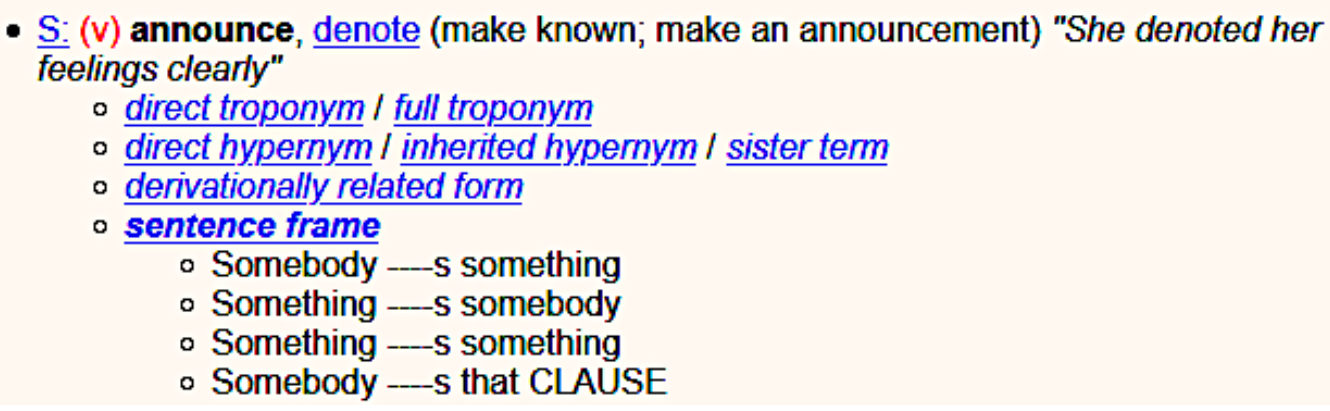

Figure 1: Sentence frames of announce

As highlighted by Fellbaum [4] "the noun slots in these syntactic frames are not at present linked to either thematic roles or semantic categories." Other resources have been used in interaction with WN to provide more information, notably FrameNet and VerbNet (see e.g. [6]), but a direct linking among these resources is not implemented in WN. In addition, sentence frames are constructed by the WN annotators based on their knowledge of the language, and the examples are not extracted from corpora.

As verbs' constructions are largely language specific, sentence frames cannot be exported from the Princeton WN when creating a new WN for a different language. For this reason, WNs available for other languages vary as to the type of syntactic information provided for verbs. Here we focus on the 
German GermaNet (https://weblicht.sfs.uni-tuebingen.de/rover/), which provides information concerning the verbs' "actual language use by giving at least one example sentence per lexical unit. In order to link lexical semantic and syntactic information, details on syntactic subcategorisation are indicated for each lexical item." The information provided is partly corpus based, as the examples are "based on the Complementation Codes provided with the German Version 2.5 of Release 2 of the CELEX Lexical database [2]." For the verb verkünden 'announce' one finds three synsets. The first synset 'öffentlich sagen' ('announce') contains three verb frames with examples:

- NN.Dn.DS - Sie verkündete, dass sie heiraten ihn würde. "She announced that she was going to get married."

- NN.Dn.AN - Der Sektenführer verkündete seinen Anhängern die frohe Botschaft. "The leader of the sect announced his followers the good news."

- NN.AN - Er verkündete die Fusion der beiden Unternehmen. "He announced the merger of the two companies."

The abbreviations in the verb frames indicate the following:

- NN: grammatical subject that is realized as a noun phrase in the nominative case

- AN: obligatory Accusative Complement

- Dn: optional Dative Complement

- DS: complement clause (dass-phrase)

The Princeton WN and GermaNet differ as to the type of language specific information they provide. Thus, GermaNet provides information about case marking, as German nouns feature morphological case. On the other hand, information about verbal aspect is available in the Princeton WN indicated by ---s / is ---ing, while it is not available in GermaNet, as verbal aspect is not grammaticalized in German.

As for language independent information, GermaNet distinguishes between complements, which can be obligatory or optional as the accusative and the dative complement in the verb frames of verkünden mentioned above, and adverbials, typically prepositional phrases, which can also be obligatory or optional. E.g. the locative PP with wohnen 'live (in a place)' annotated as BL is obligatory, while the directional PP with segeln 'sail' annotated Bd is optional. On the other hand, the fact that nominals are simply indicated by N rather than by 'someone' or 'something' as in the Princeton WN has the effect that no information is provided about the animacy feature of the fillers.

\section{Verb frames in HoDeL}

In this section, we discuss the verb frames that we have extracted from HoDeL for two verbs, pléo 'sail, float' (28 occurrences; already validated) and angéllō 'announce' (27 occurrences; not yet validated). Both verbs only feature active forms in Homer. We tentatively adapt the annotation of GermaNet adding information about animacy. Note that AG is a null subject language, but we still indicate subject NPs as $\mathrm{NN}$ (nominative NP) as the subject triggers verbal agreement (there are no impersonal forms among the occurrences analyzed here). Given the limited extent of this pilot study, for the time being we refrain from giving a complete list of tags, but only use those that reflect actual occurrences of the two verbs.

Verbal aspect is grammaticalized in AG and interacts with tense [3]. Verbs may feature three aspectual stems, the present or imperfective, the aorist or perfective, and the perfect or resultative. In addition, the future tense is not sensitive to aspect. Hence, aspectual features need to be reflected in the annotation, as well as other morphological information that turns out to be relevant for the possible occurrence of a given sentence frame. In particular, aspectual information is essential as different aspectual stems of the same verb can show different values for voice (e.g. gígnomai:PRS.M/P 'become' vs. gégona.PF.ACT). We discuss this issue in the next sections.

\subsection{Pléō}

The verb pléō comprises three synsest 'float', 'sail', 'depart' (Sec. 1; the metaphoric sense is not relevant for Homeric Greek). All occurrences feature the present stem, hence they are imperfective, here 
annotated as ...impf, except for one occurrence of the future tense. For all senses we found sentence frames 1 and 2 .

$1 \quad \mathrm{NN}(-\mathrm{a} /+\mathrm{a}) \quad \ldots$..impf

a) FLOAT

Od. 5.240

$\begin{array}{llll}\text { tá } & \text { hoi } & \text { plốoien } & \text { elaphrôs } \\ \text { DEM.NOM.PL } & \text { 3SG.DAT } & \text { float.OPT.PRS.3SG } & \text { lightly } \\ \text { 'They (=the trees) would float lightly for him.' } & \end{array}$

b) SAIL

Od. 10.80

c) DEPART

For this sense we found the relevant sentence pattern with a future tense:

$1^{\mathrm{i}} \mathrm{NN}(-\mathrm{a} /+\mathrm{a}) \quad \ldots$ fut

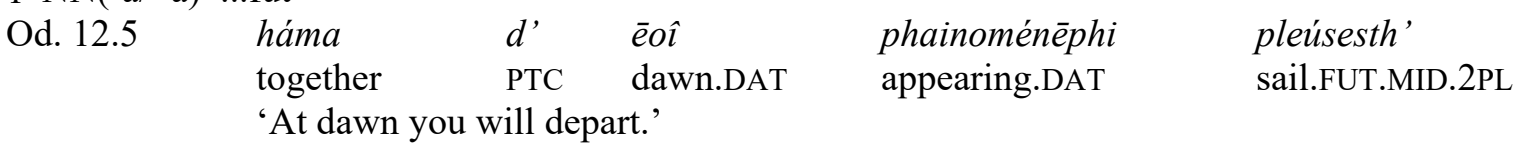

$2 \mathrm{NN}(-\mathrm{a} /+\mathrm{a}) \ldots$...impf PP

ennêmar mèn homôs pléomen
for_nine_days $\quad$ PTC alike sail.IMPF.1PL
'We sailed for nine days alike (night and day).'

b) SAIL

$2^{\mathrm{i}}$ Perlative PPs or adverbs (epì oínopa pónton 'over the wine-dark sea', Il. 7.88)

$2^{\text {ii }}$ Direction PPs

c) DEPART

Source PPs or adverbs (apò Krêtês 'from Krete' Od. 14.253; póthen 'where form?' Od. 3.71)

\subsection{Aggéllo}

The verb aggéllo is not yet fully annotated in the AGWN. Here we consider the synset \#00659537 | make known.

Syntactically, it shows a more complex set of constructions than pléo, as it can also take subordinate clauses; in addition, it features both imperfective and perfective forms (the latter annotated as aor), and several future participles. We found the following four sentence frames.

$1 \mathrm{NN}(+\mathrm{a})$...ptcp.fut/aor $\mathrm{Nd}(+\mathrm{a})$

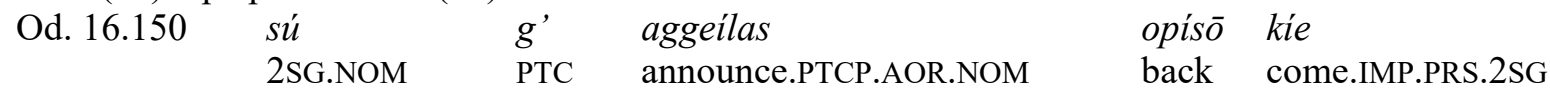

'After announcing, come back.'

Often with motion verbs: ôrto ... aggeléousa '(she) hastened announcing (aor.)'; bê d' imen aggeléōn '(he) went announcing (fut.)'

A variant of this pattern is instantiated by a finite form of the verb in a single occurrence (Il. 9.617).

$1{ }^{\mathrm{i}} \mathrm{NN}(+\mathrm{a})$...fut

$2 \mathrm{NN}(+\mathrm{a})$...impf/aor $\mathrm{Na}(-\mathrm{a}) \mathrm{Nd}(+\mathrm{a})$

$\begin{array}{llllll}\text { Il. } 15.159 & \text { Poseidáōni } & \text { ánakti } & \text { pánta } & \text { tád' } & \text { aggeîlai } \\ & \text { P.DAT } & \text { king.DAT } & \text { all.ACC.PL } & \text { DEM.ACC.PL } & \text { announce.INF.AOR }\end{array}$

'(Go) to announce all these things to kingly Poseidon.'

Variants of this frame include special values of the animacy feature.

$2^{\mathrm{i}} \mathrm{NN}(+\mathrm{a}) \mathrm{NA}(+\mathrm{a})$ 'bring information about someone' Od. 14.122-123

$2^{\mathrm{ii}} \mathrm{NN}(-\mathrm{a}) \mathrm{NA}(-\mathrm{a})$ Od. 13.93-13.94 with an inanimate subject astèr 'star' and an inanimate object pháos Eoûs 'the light of dawn'

Pattern 3 is instantiated by a single occurrence; hence the information about verbal aspect cannot be considered significant, in the light of the fact that other sentence frames allow both the imperfective and the perfective aspect. 
$3 \mathrm{NN}(+\mathrm{a}) \ldots$...aor $\mathrm{ND}(+\mathrm{a})$ INFINITIVE

\begin{tabular}{|c|c|c|c|}
\hline Od. 16.350 & $\begin{array}{l}\text { keínois } \\
\text { DEM.DAT.PL } \\
\text { néesthai } \\
\text { travel.INF.PR } \\
\text { '(That they) }\end{array}$ & $\begin{array}{l}\text { aggeílōsi } \\
\text { announce.SBJV.AOR.3PL } \\
\text { IID } \\
\text { gounce them to quickly tro }\end{array}$ & $\begin{array}{l}\text { thoôs } \\
\text { quickly }\end{array}$ \\
\hline
\end{tabular}

$4 \mathrm{NN}(+\mathrm{a})$...impf/aor COMPL CLAUSE

This sentence frame contains two subtypes that feature different types of complement clause: $4^{\mathrm{i}} \mathrm{NN}(+\mathrm{a}) \mathrm{AcI}$

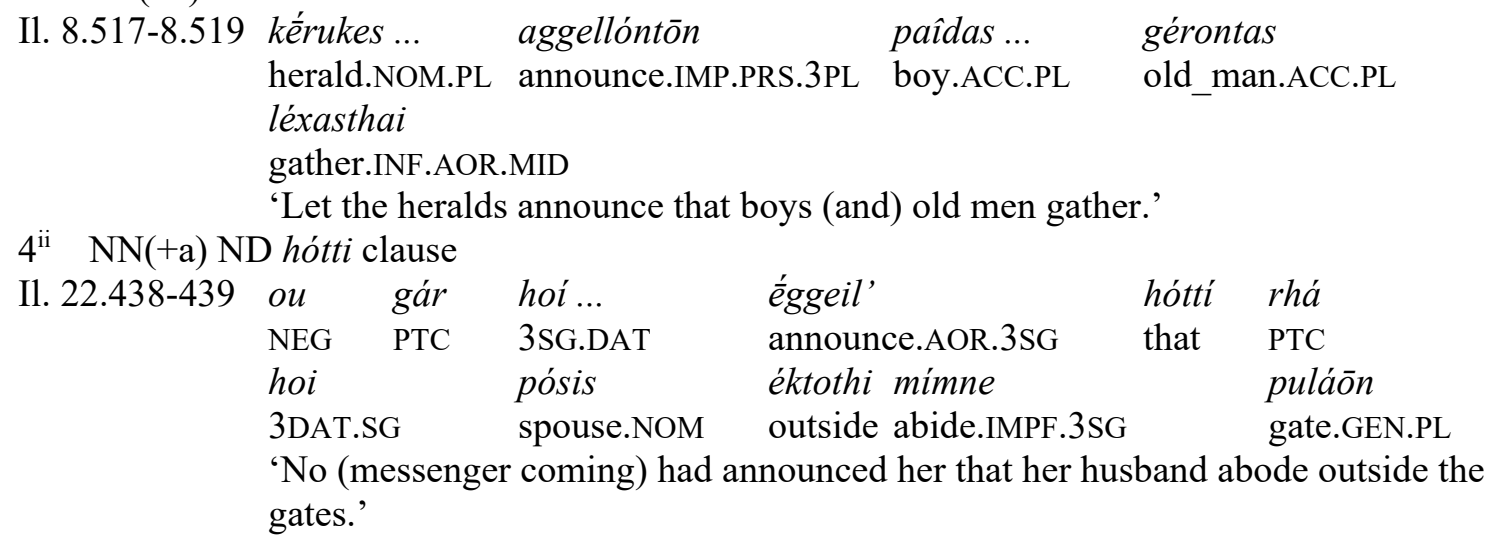

\section{Discussion}

As remarked in Sec. 5, in the description of the sentence frames we adopted the annotation from GermaNet. This implies also indicating whether NPs are obligatory or not. Clearly, we can gauge obligatoriness only based on the occurrences in the corpus on which HoDeL relies, the Homeric poems. Hence, when we indicate that the sentence frame $2^{\mathrm{ii}} \mathrm{NN}(-\mathrm{a}) \mathrm{NA}(-\mathrm{a})$ with aggéllō has an obligatory accusative object, this claim is based on a single occurrence of this pattern. Given the limited number of occurrences, we did not find cases in which an omitted direct object is definite and referential [5]. Annotating a larger corpus would also imply deciding whether such types of omitted objects must still be considered obligatory (note that we considered subjects obligatory, even when they are omitted, as anticipated in Sec. 5).

The formulaic language of the Homeric poems accounts for the comparatively high frequency of certain patterns. Indeed, some expressions occur in the same form several times in the Homeric poems, and must be considered formulas, such as occurrences of pléo with certain PPs or adverbs (e.g. énthen dè protérō pléomen 'hence we sailed forth' occurs five times in the Odyssey). Sentence frame 1 of aggéllo $\mathrm{NN}(+\mathrm{a})$ PTCP $\mathrm{Nd}(+\mathrm{a})$ shows a typical usage of the participle, which often occurs in formulas in the Homeric poems, but is not limited to formulaic language and remains widespread throughout the history of AG.

Concerning verbal aspect/tense, in spite of the limited number of occurrences some considerations can be made. The two verbs show a different aspectual profile, as pléo only features imperfective forms, while aggéllo can be used both in the imperfective and in the perfective aspect. Moreover, sentence frame 1 of aggéllō is almost only limited to participles, with a preference for the future tense ( 7 occurrences out of 9 , plus one occurrence of a finite form).

\section{Acknowledgements}

This research was carried out in the framework of the project Dipartimenti di Eccellenza 2018-2022 (Ministry of University and Research). This chapter results from joint work of the authors. For academic purposes, Erica Biagetti is responsible of Section 2, Chiara Zanchi of Section 3 and Silvia Luraghi of Sections 4 and 5. Sections 1 and 6 were written jointly by the authors. 


\section{References}

[1] Biagetti E., Zanchi C., Short W. M. (2021), Toward the creation of WordNets for ancient Indo-European languages. Proceedings of the $11^{\text {th }}$ Global WordNet Conference, S. Bosch, C. Fellbaum, M. Griesel, A. Rademaker, P. Vossen (eds), EACL/GWC, Global WordNet Association, pp.258-266.

[2] Baayen R H., Piepenbrock R., Gulikers L. (1995), CELEX2 LDC96L14. Web Download. Philadelphia: Linguistic Data Consortium.

[3] Duhoux Y. (1992), The verb in Ancient Greek [Le verbe en grec ancien]. Peeters, Louvain-La-Neuve.

[4] Fellbaum C. (ed.) (1998), WordNet: An electronic lexical database. MIT Press, Cambridge, MA.

[5] Luraghi S. (2003), Definite referential null objects in Ancient Greek. Indogermanische Forschungen 108, pp. 169-196.

[6] Shi L., Mihalcea R. (2005), Putting pieces together: Combining FrameNet, VerbNet and WordNet for robust semantic parsing. International conference on intelligent text processing and computational linguistics, pp. 100-111. Springer, Berlin.

[7] Tyler A., Evans V. (2003), The Semantics of English Prepositions: Spatial Scenes, Embodied Meanings and Cognition. CUP, Cambridge, UK.

[8] Zanchi C., Luraghi S. (2020), Presenting Hodel-A New Resource for Research On Homeric Greek Verbs. Computational Linguistics and Intellectual Technologies: Proceedings of the International Conference "Dialog 2020" [Komp'yuternaya Lingvistika i Intellektual'nye Tekhnologii: Trudy Mezhdunarodnoy Konferentsii “Dialog 2020”], Moscow, Supplementary volume, pp.1188-1201.

[9] Zanchi,C. (forthc.). The Homeric Dependency Lexicon: what it is and how to use it. Journal of Greek Linguistics. 